\title{
Pattern of Valvular Involvement in Rheumatic Heart Disease Patients in a Tertiary Care Hospital of Western Nepal
}

\author{
Ram Chandra Kafle, Vijay Madhab Alurkar , Navaraj Paudel, Girija Shankar Jha
}

${ }^{1}$ Department of Cardiology, Manipal College of Medical Sciences- Teaching Hospital, Pokhara, Nepal.

Corresponding Author Ram Chandra Kafle, Manipal College of Medical Science, Pokhara Email: drkafle30@gmail.com

\begin{abstract}
Background and Amis: Rheumatic Heart Disease (RHD) is among the commonest diseases of young adults in low-income countries like Nepal. Mitral and aortic valves are more commonly affected than others in RHD. Echocardiography is simple and cost effective tool to identify the patterns of valvular involvement that helps in diagnosis and determines the timing of surgery. This study aimed at determining the pattern of RHD in patients who underwent Echocardiography in a tertiary care hospital of western Nepal.

Methods: A retrospective analysis of trans-thoracic echocardiographic record of patients from January 2009 to December 2015 was done. Data were collected in a pre-structured proforma and analyzed.

Results: Among 12567 echocardiography, 609 (4.84\%) were recorded to have RHD including post valve replacement patients. Females predominated with male to female ratio of 1:2.8. Most patients, 308 (50\%) belonged to age group of 21-40 years. The commonest isolated lesion was mitral regurgitation (MR) in $119(26.21 \%)$ patients followed by mitral stenosis (MS) in $31(6.82 \%)$ patients. The commonest mixed lesion was MS with MR and aortic regurgitation (AR) seen in $99(21.8 \%)$. The frequency of atrial fibrillation (AF) and stroke was $18 \%$ and $3 \%$ respectively in RHD patients

Conclusions: The proportion of RHD was high in our study. Majority of RHD patients were females of reproductive age group. The commonest lesion was $\mathrm{MR}$ followed by mixed valvular lesions.
\end{abstract}

Key words: Aortic valve insufficiency; Echocardiography; Mitral valve insufficiency; Mitral valve stenosis; Rheumatic heart disease.

\section{Introduction}

Rheumatic heart disease (RHD), a preventable disease still remains a major cause of morbidity and premature death in highly active population. ${ }^{1}$ It has imposed a substantial burden on health care system of resource limited countries. ${ }^{2}$ Echocardiography is a non-invasive, easily available and cost-effective tool for diagnosis, detection of valve involvement and its severity.

RHD has devastating clinical consequences leading to long-term morbidity or mortality. A retrospective echocardiographic data analysis from eastern Nepal showed high frequency of RHD. ${ }^{3}$ Limited data across Nepal but none from western region are available in RHD patients regarding prevalence and patterns of valve involvement.

This study aims to study the Pattern of Valvular involvement in Rheumatic Heart Disease Patients in a Tertiary Care Hospital of Western Nepal.

\section{Methods}

This retrospective descriptive analysis was conducted at Manipal teaching hospital, Pokhara, a tertiary-care hospital of western Nepal. All Echocardiograms done over a period of seven years from January 2009 through December 2015 were analyzed. Permission to carry out the research and consent to review records of the patients was taken from institutional review committee. Only the first-time Echo of each patient was included for the study to avoid repetition bias and the case records with incomplete data were excluded. Hence, a total of 12567 Echo reports were included. All echocardiograms were performed in accordance with the American College of Cardiology/American Heart Association guidelines using GE Ultrasound (Vingmed Technology, model: H45011AN) systems. ${ }^{4}$ RHD cases were defined according to the World Heart Federation (WHF) criteria. ${ }^{5}$ Pre-completed case records of patients with RHD were analyzed to record relevant information including demographic data; cardiac valvular affection in a proforma. Continuous variables were expressed as mean $\pm \mathrm{SD}$, while categorical variables were expressed as frequency and percentages. Data was analyzed using SPSS for windows version 18.0.

\section{Results}

Among the 13056 Echocardiograms, 12,567 patients underwent echocardiography for the first time during these seven years. Six hundred and nine $(4.8 \%)$ patients between six and 69 years with mean age of $27 \pm 6$ years were found to have been diagnosed as RHD. Among RHD patients, $449(73.72 \%)$ cases were females and $160(26.27 \%)$ males. Out of 609 patients half were in the age group of 21-40 years, the productive population. Cases of RHD below 20 years were 109 (18\%). The cases above 50 years 
of age were either diagnosed cases earlier and under follow up with or without valve surgery or the first time presentation of symptomatic mitral stenosis. Excluding the patients with post valve replacement in follow up who were diagnosed RHD before 2009, 454 patients were analyzed for different pattern of valve involvement.

Out of 454 patients $288(63.43 \%)$ of patients had mixed valvular lesions (Table 1). MR was the most common isolated valvular lesion and found in 119 (26.27\%) cases. Isolated AR was more commonly detected in male with male to female ratio of 2.25 (Table 2).

The commonest mixed lesion was MR, MS with AR in 99(34.37\%) followed by MR and AR (Table 3). Not a single case of tricuspid stenosis (TS) was found in our study but cases of tricuspid regurgitation (TR) are not included in our study. The cases of RHD diagnosed before 2009 and undergone valve replacement/repair and in regular follow up were $155(25.45 \%)$. The frequency of atrial fibrillation (AF) and stroke was $18 \%$ and $3 \%$ respectively in RHD patients. The frequency of both AF and stroke was higher in patients with mitral valve disease especially with mitral stenosis (Table 4). The commonest valve surgery done was MVR in 78(50.32\%) cases (Figure 2). The annual rate of detection of RHD has not changed much even after 7 years (Figure 3).

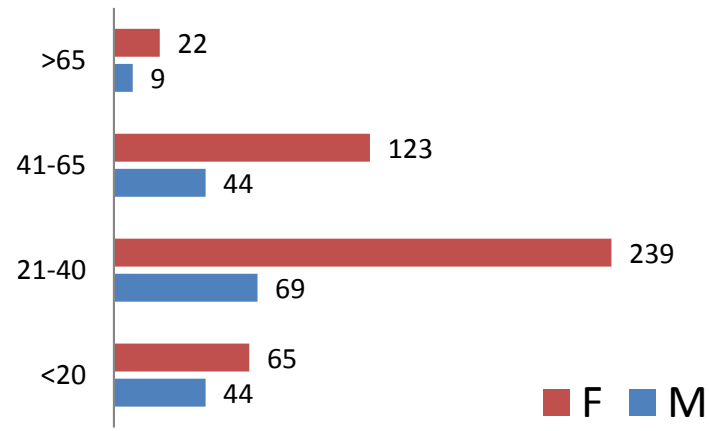

Fig 1: Age distribution of RHD patients

Table 1. Frequency of isolated and mixed valvular Lesions in rheumatic heart disease

\begin{tabular}{|lll|}
\hline Valvular lesion & Number of patients & Percentage of total \\
\hline Mixed lesion & 288 & 63.4 \\
\hline Isolated MR & 119 & 26.2 \\
\hline Isolated MS & 31 & 6.8 \\
\hline Isolated AR & 13 & 2.9 \\
\hline Isolated AS & 3 & 0.7 \\
\hline Total & 454 & $100 \%$ \\
\hline
\end{tabular}

Table 2. Results of individual valvular lesion as Sub- grouped in to pure and mixed varieties

\begin{tabular}{|llll|}
\hline Valvular lesion & $\begin{array}{l}\text { Pure } \\
(\mathbf{n}=166)\end{array}$ & $\begin{array}{l}\text { Mixed } \\
(\mathbf{n}=769)\end{array}$ & $\begin{array}{l}\text { Total } \\
(\mathbf{n}=935)\end{array}$ \\
\hline Mitral regurgitation & 119 & 266 & 385 \\
\hline Aortic regurgitation & 13 & 238 & 251 \\
\hline Mitral stenosis & 31 & 201 & 232 \\
\hline Aortic stenosis & 3 & 64 & 67 \\
\hline
\end{tabular}

Table 3. Frequency of combination valvular lesions present in 288 patients with mixed valvular lesions

\begin{tabular}{lll}
$\begin{array}{l}\text { Combinations of } \\
\text { valvular lesions }\end{array}$ & $\begin{array}{l}\text { Frequency } \\
(\mathbf{n}=\mathbf{2 8 8})\end{array}$ & Percentage (\%) \\
\hline MR,MS,AR & 99 & 34.4 \\
\hline MR,AR & 69 & 23.9 \\
\hline MS,MR & 53 & 18.4 \\
\hline MS,MR,AR,AS & 27 & 9.4 \\
\hline Others & 40 & 13.9
\end{tabular}

Table 4. Atrial fibrillation and Stroke in different valvular lesions

\begin{tabular}{|lll|}
\hline Valve lesions & AF & Stroke \\
\hline Mitral valve disease & 51 & 11 \\
\hline Aortic valve disease & 5 & 0 \\
\hline Mitral + Aortic valve disease & 38 & 6 \\
\hline Post valve replacement & 15 & 2 \\
\hline MS versus non MS lesions & & \\
\hline MS + any other & 89 & 17 \\
\hline Any other without MS & 20 & 2 \\
\hline
\end{tabular}

\section{Valve replacement/post-surgery}

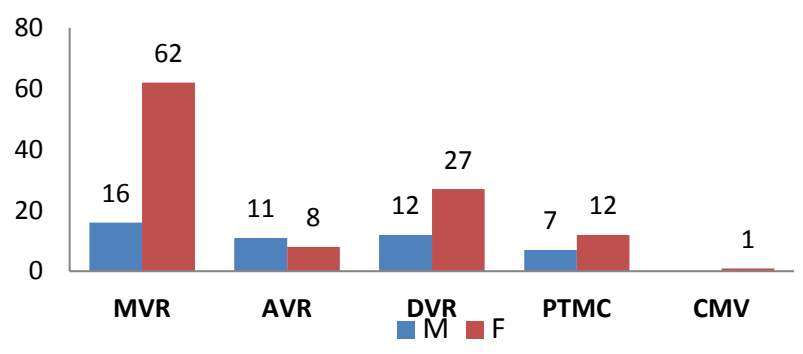

Fig 2: RHD patients with valve replacement or post-surgery

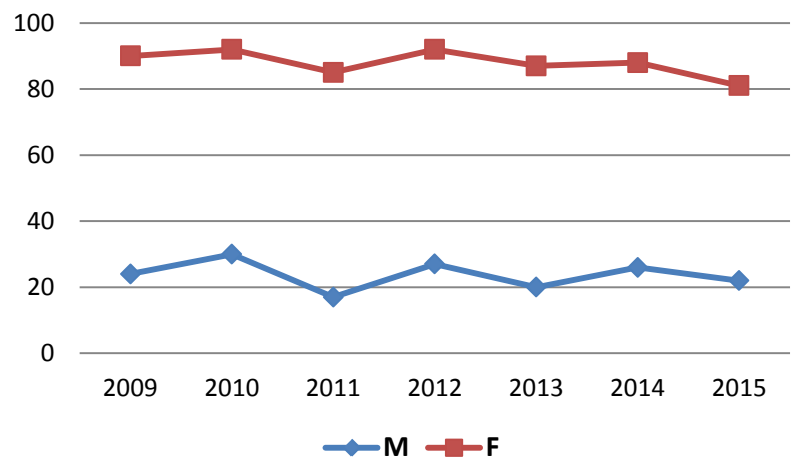

Fig 3: Rate of annual detection of RHD 


\section{Discussion:}

Although in western countries RHD is now very rare, it remains a major public health problem in developing countries like Nepal. ${ }^{6}$ It is one of the major causes of cardiovascular disease related admissions and important indication for cardiac surgery in under developed countries. ${ }^{7}$

The frequency of RHD was high (4.84\%) in our study population which is similar to study by Amjad Abrar et al $(5.7 \%)^{8}$ and Sharma $\mathrm{M}$ et $\mathrm{al}^{9}$ but lower than the study by Shrestha N. et al $(15.8 \%) 3$ and by Mahmoud U Sani et al $(9.8 \%) .{ }^{10}$ Disease has affected the productive population of 21-40 years in half of the cases. The pattern of valvular involvement was similar to that of study by C.N. Manjunath et al. ${ }^{11}$

In a study conducted on school children in Cambodia and Mozambique, the case detection rate by echocardiography was approximately 10 times higher than that achieved by clinical examination only. ${ }^{12}$ Recurrences of rheumatic fever are higher in patients with RHD and each episode of acute rheumatic fever leads to further damage to the valves. ${ }^{13}$

When considering individual valves, mitral valve was the most commonly affected valve in our study which coincides with the findings of other studies that Mitral regurgitation was the predominant valvular lesion. ${ }^{14,15,16}$ But the cause for predominance of mitral valve involvement by the disease is uncertain. ${ }^{17,18}$

Mitral stenosis found in 232 patients, though the isolated cases were only 31 , significantly increases the risk of Atrial fibrillation and AF confers a substantial risk of stroke. Currently, "valvular AF" refers to patients with mitral stenosis or artificial heart valves. Valvular heart diseases, such as mitral regurgitation, aortic stenosis (AS) and aortic insufficiency, do not result in conditions of low flow in the left atrium, and do not apparently increase the risk of thromboembolism brought by AF compared to mitral stenosis. ${ }^{19,20}$ So many of our cases are predisposed to thromboembolic complication.

One fourth of all cases had to undergo some surgical procedure either reparative or valve replacement adding of economic burden to the society. Unchanged pattern of rate annual detection of RHD cases over last seven years indicate high burden of cases in community.

There are few limitations of our study. This is a hospital based study; the results may not be the true representation of community. The analyzed data are retrospective data of selected patients referred for echocardiography. The reason for echocardiography and symptoms at presentation could not be assessed.

\section{Conclusion:}

RHD is still prevalent in high proportion affecting the productive population in our study. The commonest isolated lesion was MR followed by mixed valvular lesions. Preventive strategies aimed at screening programs at community level, early detection and treatment of RHD can contribute in reduction of disease burden and its sequelae.

\section{References}

1. Rheumatic fever and Rheumatic heart disease. World health organ Tech Rep Series 2004; 923: 1-22.

2. Rheumatic fever and rheumatic heart disease. Report of WHO study group. Technical report series No. 764, Geneva WHO, 1998.

Cite this article as: Ram Chandra Kafle, Vijay Mohan Alurkar, Navaraj Paudel, et al. Pattern of Valvular involvement in Rheumatic Heart Disease Patients in a Tertiary Care Hospital of Western Nepal.Nepalese heart Journal 2016;13(2): 29-31.
3. NR Shrestha, T Pilgrim, P Karki, et al. Rheumatic Heart disease Revisited: Patterns of Valvular Involvement from a Consecutive Cohort in Eastern Nepal. J Cardiovasc Med (Hagerstown). 2012 ;13(11):755-59.

4. MD Cheitlin, JS Alpert, WF Armstrong. ACC/AHA guideline for the clinical application of echocardiography: A report of the American College of Cardiology/American Heart Association Task force on Practice guideline (Committee on clinical Application of Echocardiography). Circulation 1997; 95: 1686-87

5. B Reményi , N Wilson, A Steer et al. World Heart Federation criteria for echocardiographic diagnosis of rheumatic heart disease--an evidence-based guideline. Nat Rev Cardiol. 2012; 9(5):297-309.

6. PS Douglas, E Foster, J Gorscan. ACC/AHA clinical competence statement on echocardiography. A report of the American College of Cardiology/American Heart Association/American College of Physicians/American Society of internal medicine. Task force on clinical competence ( Committee of Echocardiography) J Am Coll Cardiol 2003; 41: 687-89

7. PR Regmi, MR Pandey. Rheumatic fever and RHD in school children of Kathmandu city. Indian Heart J 1997; 49: 518-20.

8. AAbrar, S Khan, MU Rehman, et al. Frequency of rheumatic heart disease in patients undergoing echocardiography in district Dera Ismail Khan. J Med Sci 2014; 12:147-50.

9. M Sharma, A Saxena, SS Kothari. Acute rheumatic fever in children: experience from a cardiac centre. Indian Heart J 1999; 51: 652-53.

10. US Mahmoud, MK Kamilu. , MB Musa. Prevalence and pattern of rheumatic heart disease in the Nigerian savannah: an echocardiographic study Cardiovasc J Afr. 2007; 18(5): 295-9.

11. CN Manjunath, P Srinivas, KS Ravindranath, et al. Incidence and patterns of valvular heart disease in a tertiary care high-volume cardiac center: A single center experience Indian Heart J. 2014; 66(3): 320-326.

12. E Marijon, P Ou, DS Celermajer et al. Prevalence of rheumatic heart disease detected by echocardiographic screening. N Engl J Med 2007; 357:470-6.

13. T Mason, M Fisher, G Kujala. Acute Rheumatic fever in West Virginia - not just a disease of children. Arch Intern Med 1991; 151:133-6.

14. HAAurakzai, SHameed,A Shahbaz, etal.Echocardiographic profile of rheumatic heart disease At a tertiary cardiac centre. J Ayub Med Coll Abbottabad 2009; 21:122-6.

15. MA Sheikh. Cardiac Valvular lesions in patients with Rheumatic Heart Disease. J Pak Inst Med Sci 2004; 15: 862-65.

16. Khalilullah, SA Ahmed, S Badsha, et al. Rheumatic Heart disease A study of surgically excised cardiac valves and biopsies. J Coll Physician Surg Pak 2002; 12: 542-45.

17. S Jadoon, $\mathbf{N}$ Haider, $M$ Hassan. Retrospective analysis of 54 patients with acute rheumatic fever. Pak Paed J 2003; 27 : 118-20.

18. MS Ravisha, MS Tullur, JR Kamat. Rheumatic fever and RHD; clinical profile of 550 cases in India. Arch Med Res 2003; 34: 382-87.

19. SK Sharma, SH Verma . A Clinical Evaluation of Atrial Fibrillation in Rheumatic Heart Disease. J Assoc Physicians India. 2015;63(6):22-25.

20. L Fauchier, R Philippart, N Clementy, et al. How to define valvular atrial fibrillation? Arch Cardiovasc Dis. 2015;108(10):530-39. 